\title{
A vibrational spectroscopic study of the copper bearing silicate mineral luddenite
}

\author{
Ray L. Frost ${ }^{\mathrm{a}, *}$, Andrés López ${ }^{\mathrm{a}}$, Yunfei Xi ${ }^{\mathrm{a}}$, Ricardo Scholz ${ }^{\mathrm{b}}$

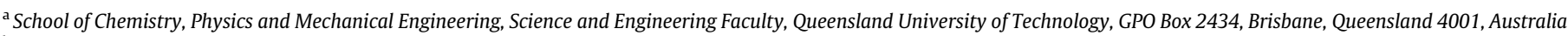 \\ ${ }^{\mathrm{b}}$ Geology Department, School of Mines, Federal University of Ouro Preto, Campus Morro do Cruzeiro, Ouro Preto, MG 35,400-00, Brazil
}

\section{H I G H L I G H T S}

- We have studied the copper-lead silicate mineral luddenite using vibrational spectroscopy.

- This mineral is only one of many silicate minerals containing copper.

- Stretching vibrations of hydroxyl units suggest hydroxyl units exist in the structure of luddenite.
G R A P H I C A L A B S T R A C T

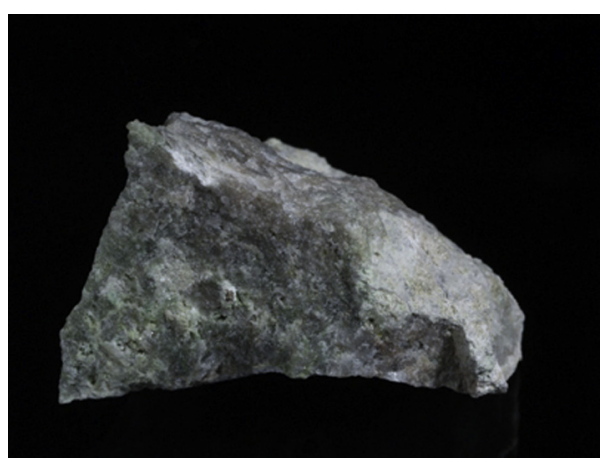

\section{A B S T R A C T}

The molecular structure of the copper-lead silicate mineral luddenite has been analysed using vibrational spectroscopy. The mineral is only one of many silicate minerals containing copper. The intense Raman band at $978 \mathrm{~cm}^{-1}$ is assigned to the $v_{1}\left(A_{1 \mathrm{~g}}\right)$ symmetric stretching vibration of $\mathrm{Si}_{5} \mathrm{O}_{14}$ units. Raman bands at 1122,1148 and $1160 \mathrm{~cm}^{-1}$ are attributed to the $v_{3} \mathrm{SiO}_{4}$ antisymmetric stretching vibrations. The bands in the $678-799 \mathrm{~cm}^{-1}$ are assigned to OSiO bending modes of the $\left(\mathrm{SiO}_{3}\right)_{n}$ chains. Raman bands at 3317 and $3329 \mathrm{~cm}^{-1}$ are attributed to water stretching bands. Bands at 3595 and $3629 \mathrm{~cm}^{-1}$ are associated with the stretching vibrations of hydroxyl units suggesting that hydroxyl units exist in the structure of luddenite.

(c) 2014 Elsevier B.V. All rights reserved.
Luddenite

Copper silicate

Raman spectroscopy

Infrared spectroscopy

\section{Introduction}

The mineral luddenite is a hydrated silicate mineral of lead and copper of formula $\mathrm{Cu}_{2} \mathrm{~Pb}_{2} \mathrm{Si}_{5} \mathrm{O}_{14} \cdot 4 \mathrm{H}_{2} \mathrm{O}$ [1]. It is one of several copper silicates [2]. There are a significant number of silicate minerals which have copper as one of the main cations. These include kinoite $\mathrm{Ca}_{2} \mathrm{Cu}_{2} \mathrm{Si}_{3} \mathrm{O}_{10}(\mathrm{OH})_{4}$ [3], chrysocolla $\left(\mathrm{Cu}, \mathrm{Al}_{2}\right)_{2} \mathrm{H}_{2} \mathrm{Si}_{2} \mathrm{O}_{5}(\mathrm{OH})_{4} \cdot \mathrm{nH}_{2} \mathrm{O}$ [4,5], dioptase $\mathrm{CuSiO}_{3} \cdot \mathrm{H}_{2} \mathrm{O}$ [6], planchéite $\mathrm{Cu}_{8} \mathrm{Si}_{8} \mathrm{O}_{22}(\mathrm{OH})_{4} \cdot \mathrm{H}_{2} \mathrm{O}$ [7], shattuckite $\mathrm{Cu}_{5}\left(\mathrm{SiO}_{3}\right)_{4}(\mathrm{OH})_{2} \quad[8]$, whelanite $\mathrm{Ca}_{5} \mathrm{Cu}_{2}(\mathrm{OH})_{2} \mathrm{CO}_{3}$,

\footnotetext{
* Corresponding author. Tel.: +61 73138 2407; fax: +61 731381804 .

E-mail address: r.frost@qut.edu.au (R.L. Frost).
}

$\mathrm{Si}_{6} \mathrm{O}_{17} \cdot 4 \mathrm{H}_{2} \mathrm{O}$ [9], ajoite (K,Na) $\mathrm{Cu}_{7} \mathrm{AlSi}_{9} \mathrm{O}_{24}(\mathrm{OH})_{6} \cdot 3 \mathrm{H}_{2} \mathrm{O}$ [10], apachite $\mathrm{Cu}_{9} \mathrm{Si}_{10} \mathrm{O}_{29} \cdot 11 \mathrm{H}_{2} \mathrm{O}$ [10], papagoite $\mathrm{CaCuAlSi}{ }_{2} \mathrm{O}_{6}(\mathrm{OH})_{3}$ [11]. Apart from chrysocolla which appears as a normally amorphous mineral, all of these copper silicate minerals are crystalline; however the crystallinity may vary between the minerals. All of the minerals contain either hydroxy units or water units or both. These water and $\mathrm{OH}$ units are important for the stability of the minerals. All these minerals are of various shades of blue. This study of the mineral luddenite adds to our knowledge of silicate minerals containing copper.

Luddenite is a rare secondary mineral that forms from the oxidation of other secondary copper minerals in copper-rich 
base-metal deposits in massive fracture coatings, in vein fillings, and in vugs. It is related to other copper silicate minerals such as shattuckite. Luddenite was first found at Artillery Peak, Mohave County, Arizona, USA. Despites the type locality, only few occurrences were described in literature [12].

Luddenite is monoclinic with $a=7.85 \AA, \quad b=20.06 \AA$, $c=14.72 \AA$, with $\beta=90.78^{\circ}$ and $Z=6$ [1]. The mineral is light green in colour, sometimes said to be nickel green, and may be associated with alamosite $\mathrm{PbSiO}_{3}[13,14]$ and wickenburgite $\mathrm{Pb}_{3} \mathrm{Al}\left[\mathrm{CaAlSi}_{10} \mathrm{O}_{27}\left(\mathrm{H}_{2} \mathrm{O}\right)_{3}\right] \cdot \mathrm{H}_{2} \mathrm{O}$. The mineral is found in totally oxidised $\mathrm{Pb}-\mathrm{Cu}$ sulphide ores.

The aim of this paper is to report the Raman spectra of welldefined natural luddenite mineral, and to relate the spectra of this molecule to the crystal structure. This paper follows the systematic research of the large group of oxyanion containing minerals, and especially their molecular structure using vibrational spectroscopy.

\section{Experimental}

Samples description and preparation

The luddenite sample studied in this work forms part of the collection of the Geology Department of the Federal University of Ouro Preto, Minas Gerais, Brazil, with sample code SAC-001. The mineral originated from Artillery Peak, Mohave County, Arizona, USA. The studied sample occurs in association with wickenburgite and the separation of different minerals was done with a stereomicroscope Zeiss model Stemi DV4 from the Museu de Ciência e Técnica, School of Mines of the Federal University of Ouro Preto.

\section{Raman microprobe spectroscopy}

Crystals of luddenite were placed on a polished metal surface on the stage of an Olympus BHSM microscope, which is equipped with $10 \times, 20 \times$, and $50 \times$ objectives. The microscope is part of a Renishaw 1000 Raman microscope system, which also includes a monochromator, a filter system and a CCD detector (1024 pixels). The Raman spectra were excited by a Spectra-Physics model 127 He-Ne laser producing highly polarised light at $633 \mathrm{~nm}$ and collected at a nominal resolution of $2 \mathrm{~cm}^{-1}$ and a precision of $\pm 1 \mathrm{~cm}^{-1}$ in the range between 200 and $4000 \mathrm{~cm}^{-1}$. Repeated acquisitions on the crystals using the highest magnification $(50 \times)$ were accumulated to improve the signal to noise ratio of the spectra. Raman Spectra were calibrated using the $520.5 \mathrm{~cm}^{-1}$ line of a silicon wafer. Clearly the crystals of luddenite are readily observed, with gem quality, making the Raman spectroscopic measurements readily obtainable.

\section{Infrared spectroscopy}

Infrared spectra were obtained using a Nicolet Nexus 870 FTIR spectrometer with a smart endurance single bounce diamond ATR cell. Spectra over the $4000-525 \mathrm{~cm}^{-1}$ range were obtained by the co-addition of 128 scans with a resolution of $4 \mathrm{~cm}^{-1}$ and a mirror velocity of $0.6329 \mathrm{~cm} / \mathrm{s}$. Spectra were co-added to improve the signal to noise ratio.

Spectral manipulation such as baseline correction/adjustment and smoothing were performed using the Spectracalc software package GRAMS (Galactic Industries Corporation, NH, USA). Band component analysis was undertaken using the Jandel 'Peakfit' software package that enabled the type of fitting function to be selected and allows specific parameters to be fixed or varied accordingly. Band fitting was done using a Lorentzian-Gaussian cross-product function with the minimum number of component bands used for the fitting process. The Gaussian-Lorentzian ratio was maintained at values greater than 0.7 and fitting was undertaken until reproducible results were obtained with squared correlations of $r^{2}$ greater than 0.995 .

\section{Results and discussion}

\section{Vibrational spectroscopy}

The Raman spectrum of luddenite over the $100-4000 \mathrm{~cm}^{-1}$ spectral; range is reported in Fig. 1a. This figure shows the position and relative intensity of the Raman bands. It is noted that there some very low intensity bands in the $\mathrm{OH}$ stretching region. In order to closely identify and assign the Raman peaks, the spectrum is subdivided into sections based upon the type of vibration being analysed. The infrared spectrum of luddenite over the 500$4000 \mathrm{~cm}^{-1}$ spectral range is reported in Fig. 1b. This spectrum displays the position and relative intensity of the infrared bands. A comparison may be made between the Raman and infrared spectra. It is note that there is significantly more intensity in the $\mathrm{OH}$ stretching region in the infrared spectrum. The infrared spectrum may be subdivided into subsections based upon the type of vibration being studied.

The Raman spectrum of luddenite over the $750-1200 \mathrm{~cm}^{-1}$ spectral range is illustrated in Fig. 2a. The spectrum may be subdivided into three sections (a) Raman bands centred around $800 \mathrm{~cm}^{-1}$, (b) the Raman band at $978 \mathrm{~cm}^{-1}$ and (c) the series of bands at around $1150 \mathrm{~cm}^{-1}$. The intense Raman band at $978 \mathrm{~cm}^{-1}$ is assigned to the $v_{1}\left(A_{1 \mathrm{~g}}\right)$ symmetric stretching vibration of $\mathrm{Si}_{5} \mathrm{O}_{14}$ units. Dowty showed that the $-\mathrm{SiO}_{3}$ units had a unique band position of $980 \mathrm{~cm}^{-1}$ [15] (see Figs. 2 and 4 of this reference). Dowty calculated the position of infrared bands for silicate structures and also showed measured spectra of the equivalent
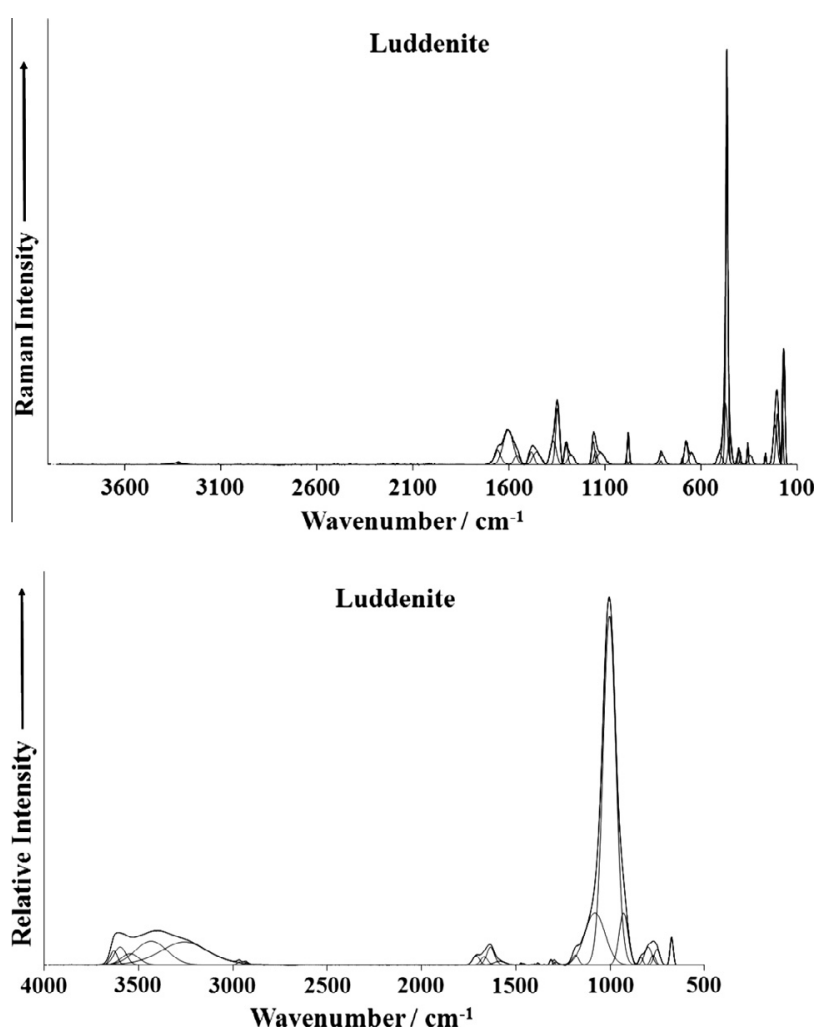

Fig. 1. (a) Raman spectrum of Luddenite (upper spectrum) and (b) infrared spectrum of Luddenite (lower spectrum). 

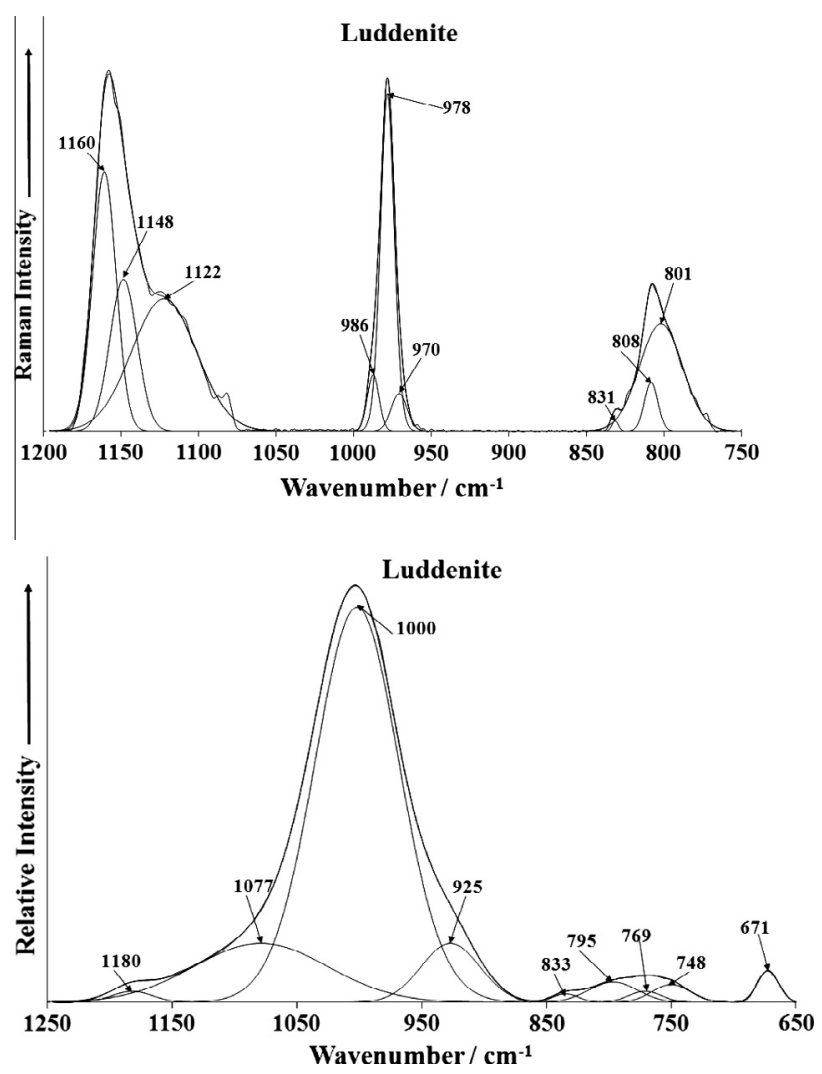

Fig. 2. (a) Raman spectrum of Luddenite (upper spectrum) in the $750-1200 \mathrm{~cm}^{-1}$ spectral range and (b) infrared spectrum of Luddenite (lower spectrum) in the 650$1250 \mathrm{~cm}^{-1}$ spectral range.
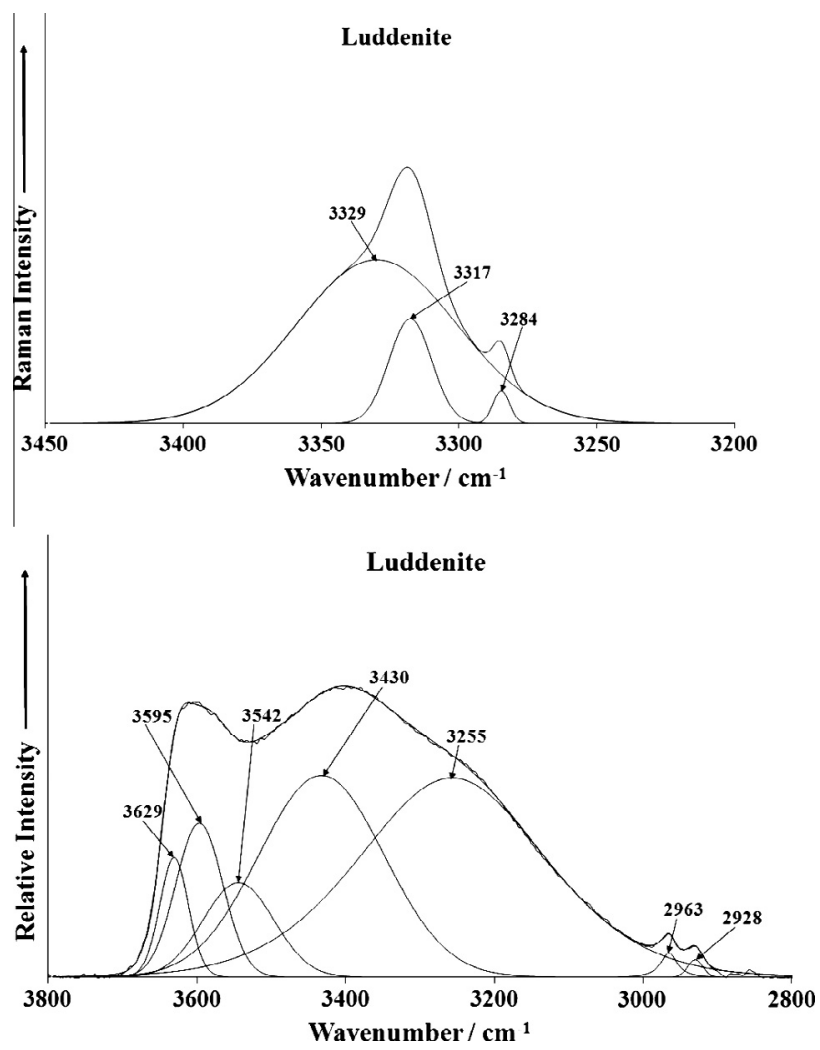

Fig. 4. (a) Raman spectrum of Luddenite (upper spectrum) in the $3200-3450 \mathrm{~cm}^{-1}$ spectral range and (b) infrared spectrum of Luddenite (lower spectrum) in the $2800-3800 \mathrm{~cm}^{-1}$ spectral range.
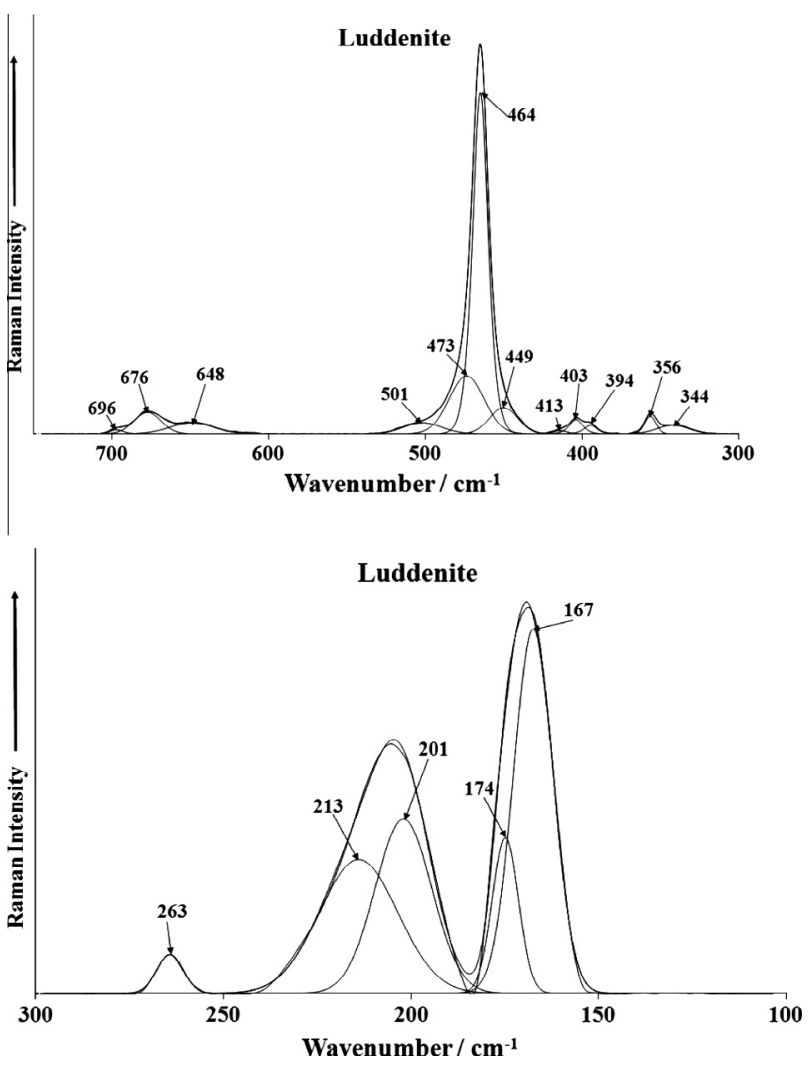

Fig. 3. (a) Raman spectrum of Luddenite (upper spectrum) in the $300-750 \mathrm{~cm}^{-1}$ spectral range and (b) Raman spectrum of Luddenite (lower spectrum) in the 100$300 \mathrm{~cm}^{-1}$ spectral range.

theoretical system. The bands in the $678-799 \mathrm{~cm}^{-1}$ are assigned to OSiO bending modes of the $\left(\mathrm{SiO}_{3}\right)_{n}$ chains. The infrared spectra as displayed by Dowty show considerable width in the peaks.

The Raman bands at 1122,1148 and $1160 \mathrm{~cm}^{-1}$ are attributed to the $v_{3} \mathrm{SiO}_{4}$ antisymmetric stretching vibrations. The splitting of the $v_{3}$ vibrational mode offers support to the concept that the $\mathrm{SiO}_{4}$ tetrahedrons in luddenite are strongly distorted. The Raman band centred upon $801 \mathrm{~cm}^{-1}$ is ascribed to water librational bands. The infrared spectrum (Fig. 2b) is dominated by a very broad band at $1000 \mathrm{~cm}^{-1}$. Shoulder bands of this peak are found at 925,1077 and $1180 \mathrm{~cm}^{-1}$. In addition, some low intensity infrared bands are found at $748,769,795$ and $833 \mathrm{~cm}^{-1}$. In harmony with the assignment of the Raman bands in this spectral region, the bands are attributed to water librational modes.

The Raman spectra of luddenite over the 300-750 and the 100$300 \mathrm{~cm}^{-1}$ spectral range are reported in Fig. 3. Strong Raman bands are noted at 167, 174, 201, 213 and $263 \mathrm{~cm}^{-1}$. These bands are attributed to external vibrations. A strong Raman band at $464 \mathrm{~cm}^{-1}$ with shoulder bands at 449,473 and $501 \mathrm{~cm}^{-1}$ are assigned to the $\mathrm{SiO}_{4} v_{2}$ bending mode. For a perfectly symmetric $\mathrm{SiO}_{4}$ tetrahedron, only a single band at $608 \mathrm{~cm}^{-1}\left(A_{2 \mathrm{u}}\right)$ should be observed. The Raman band observed at $676 \mathrm{~cm}^{-1}$ with additional bands at 648 and $696 \mathrm{~cm}^{-1}$ is assigned to the $\mathrm{SiO}_{4} v_{4}$ bending mode. Vedanand et al. [16] reported the $v_{2}$ and $v_{4}$ modes for stringhamite at 510 and $660 \mathrm{~cm}^{-1}$.

The Raman spectrum of luddenite over the $3200-3450 \mathrm{~cm}^{-1}$ spectral range is reported in Fig. 4a. This spectrum suffers from a lack of signal; nevertheless Raman bands may be resolved at 3317 and $3329 \mathrm{~cm}^{-1}$. A shoulder band is also found at $3284 \mathrm{~cm}^{-1}$. These bands are attributed to water stretching bands. The infrared spectrum of luddenite over the $2800-3800 \mathrm{~cm}^{-1}$ spectral range is reported in Fig. $4 \mathrm{~b}$. The spectral profile is broad and 

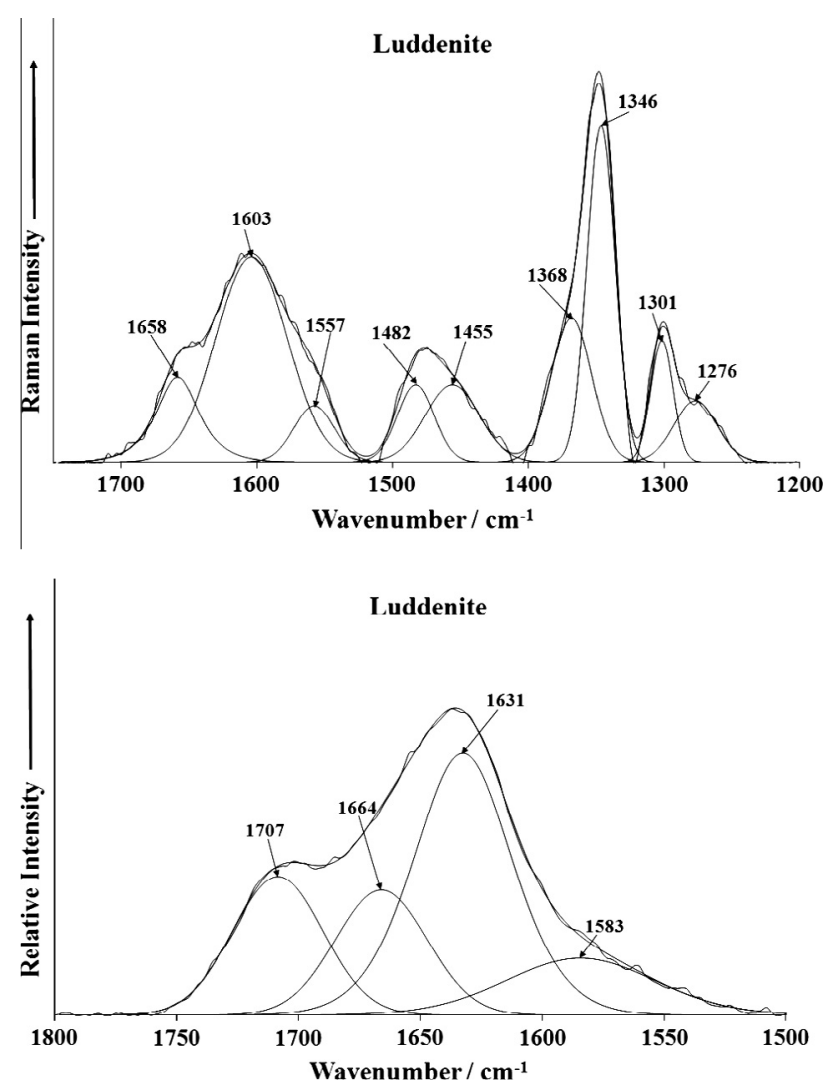

Fig. 5. (a) Raman spectrum of luddenite (upper spectrum) in the $1200-1750 \mathrm{~cm}^{-1}$ spectral range (b) infrared spectrum of luddenite (lower spectrum) in the 1500$1800 \mathrm{~cm}^{-1}$ spectral range.

infrared bands may be resolved at 3255, 3430, 3542, 3595 and $3629 \mathrm{~cm}^{-1}$. These bands are assigned to water stretching vibrations. However, the positions of the two bands at 3595 and $3629 \mathrm{~cm}^{-1}$ suggest that these two bands may be associated with the stretching vibrations of hydroxyl units. The two low intensity infrared bands at 2928 and $2963 \mathrm{~cm}^{-1}$ are ascribed to organic compounds and are due to $\mathrm{CH}$ stretching vibrations.

The Raman spectrum of luddenite over the $1200-1800 \mathrm{~cm}^{-1}$ spectral range is shown in Fig. 5a. The two Raman bands observed at 1603 and $1658 \mathrm{~cm}^{-1}$ are assigned to the water bending modes. Other Raman bands are identified at 1276, 1301, 1346 and $1368 \mathrm{~cm}^{-1}$ and are attributed to the antisymmetric stretching modes of siloxane units $\left(\mathrm{Si}_{5} \mathrm{O}_{14}\right)$. Two other Raman bands are noted at 1455 and $1482 \mathrm{~cm}^{-1}$. The Raman spectrum in this spectral region shows significantly more bands than the infrared spectrum as shown in Fig. 5b. Infrared bands are observed at 1631, 1664 and $1707 \mathrm{~cm}^{-1}$ with a long tail centred at $1583 \mathrm{~cm}^{-1}$. These bands are assigned to water bending modes. The observation of the three bands provides support for water existing in different molecular environments subject to different hydrogen bond strengths. The infrared band at $1631 \mathrm{~cm}^{-1}$ is assigned to the water bending mode of weakly hydrogen bonded water. The infrared band at $1664 \mathrm{~cm}^{-1}$ is ascribed to water involved in strongly hydrogen bonding; whereas the band at $1707 \mathrm{~cm}^{-1}$ is attributed to very highly strongly bonded water.

\section{Conclusions}

The mineral luddenite is a rare mineral noted for its colour variation including an emerald green colour. The mineral has been analysed by using a combination of scanning electron microscopy with energy dispersive analysis and Raman and infrared spectroscopy. The mineral is fundamentally a silicate mineral of $\mathrm{Cu}$ and $\mathrm{Pb}$.

Raman spectroscopy identifies stretching and bending vibrations of the $\mathrm{Si}_{2} \mathrm{O}_{5}$ and $\mathrm{Si}_{2} \mathrm{O}_{7}$ units. Raman bands attributable to trigonal boron are observed. Infrared spectra show much greater complexity making their assignment more difficult. Two Raman bands at 3547 and $3612 \mathrm{~cm}^{-1}$ are assigned to $\mathrm{OH}$ stretching bands. Bands associated with water stretching vibrations are observed in the spectra of luddenite. Vibrational spectroscopy enables aspects of the molecular structure of luddenite to be ascertained.

\section{Acknowledgements}

The financial and infra-structure support of the Discipline of Nanotechnology and Molecular Science, Science and Engineering Faculty of the Queensland University of Technology, is gratefully acknowledged. The Australian Research Council (ARC) is thanked for funding the instrumentation. The authors would like to acknowledge the Center of Microscopy at the Universidade Federal de Minas Gerais (http://www.microscopia.ufmg.br) for providing the equipment and technical support for experiments involving electron microscopy.

\section{References}

[1] S.A. Williams, Mineral. Mag. 46 (1982) 363.

[2] C. Guillebert, T. Le Bihan, Bulletin de la Societe Francaise de Mineralogie et de Cristallographie 88 (1965) 119.

[3] R.L. Frost, Y. Xi, Spectrochim. Acta Part A Mol. Biomol. Spectrosc. 89 (2012) 88.

[4] R.L. Frost, Y. Xi, Vib. Spectrosc. 64 (2013) 33.

[5] R.L. Frost, Y. Xi, B.J. Wood, Thermochim. Acta 545 (2012) 157.

[6] R.L. Frost, Y. Xi, J. Therm. Anal. Calorim. 112 (2013) 615.

[7] L. Frost Ray, Y. Xi, Spectrochim. Acta Part A Mol. Biomol. Spectrosc. 91C (2012) 314.

[8] L. Frost Ray, Y. Xi, Spectrochim. Acta Part A Mol. Biomol. Spectrosc. 87 (2012) 241.

[9] L. Frost Ray, Y. Xi, Spectrochim. Acta Part A Mol. Biomol. Spectrosc. 91C (2012) 319.

[10] R.L. Frost, Y. Xi, J. Mol. Struct. 1018 (2012) 72.

[11] R.L. Frost, Y. Xi, Spectrosc. Lett. (ahead of print).

[12] F. Brandstätter, T. Hirche, G. Niedermayr, F. Walter, Carinthia II (2010) 199 200./120.

[13] M.L. Boucher, D.R. Peacor, Zeitschrift fuer Kristallographie, Kristallgeometrie, Kristallphysik, Kristallchemie 126 (1967) 98.

[14] A.L. Mackay, Mineral. Mag. J. Mineral. Soc. 29 (1952) 933 (1876-1968).

[15] E. Dowty, Phys. Chem. Miner. 14 (1987) 80.

[16] S. Vedanand, B.J. Reddy, Y.P. Reddy, Solid State Commun. 77 (1991) 231. 